Worwod, A. J. (1954). J. gen. Microbiol. 10, 509-520.

\title{
The Inhibition of Bacterial Growth by Colloidal Heavy- metal Sulphides and by Colloidal Sulphur
}

\author{
By A. J. WOIWOD \\ Wellcome Research Laboratories (Biological Division), Beckenham, Kent
}

SUMMARY : Colloidal copper sulphide is inhibitory to staphylococci and a number of other Gram-positive organisms, but has little effect on Gram-negative organisms. Its formation when cystine and peptides containing cystine are autoclaved with copper is thought to be responsible for the anti-staphylococcal activity of heatsterilized copper-containing peptone solutions. Colloidal sulphur is active against the cocci but the inhibition differs in some respects from that of copper sulphide, notably in the ease with which it can be reversed by cystine, cysteine and mercaptoacetic (thioglycollic) acid. Iron and manganese sulphides also inhibit bacterial growth and the possible significance of this inhibition on the production of anaerobic toxins is discussed.

The failure of some bacteria to grow readily from small inocula in laboratory media was shown by O'Meara \& Macsween $(1936,1937)$ to be due to copper present as an impurity in their peptone. The present investigation was undertaken to determine the reason for this inhibitory effect of copper, particularly for Staphylococcus aureus which O'Meara \& Macsween showed was a susceptible organism.

\section{METHODS}

Organisms used. Staphylococcus aureus CN 59 (Wellcome Bacterial Collection) was used to test for inhibition. Representative strains of other species of bacteria from the collection were used in the later stages of the work when the inhibitory factor had been identified and a survey of the sensitivity of microorganisms to this substance was being made.

Experimental procedure. Inhibition was detected by inoculating the medium with falling tenfold dilutions of the test organism, the initial suspension having been adjusted to match Brown's opacity tube no. $3\left(1 \cdot 8 \times 10^{9}\right.$ organisms $/ \mathrm{ml}$. for Staph. aureus). The dilutions were made in quarter-strength Ringer's solution, and $1 \mathrm{ml}$. of each dilution was added to $9 \mathrm{ml}$. of medium, three tubes being inoculated at each dilution over the range $10^{-1}$ to $10^{-9}$. The full range of dilutions was not always necessary and was adjusted to suit the experiment. Growth was examined after 24 and $48 \mathrm{hr}$. of incubation.

Media. For work with acid-hydrolysed casein and also for studying the effect of copper on individual media constituents the following medium, modified from one which supported growth of a wide range of micro-organisms (Proom \& Woiwod, 1949) was used:

$\begin{array}{ll}\text { Acid hydrolysed casein } & 20 \cdot 0 \mathrm{~g} . \\ \text { Tryptophan } & 0 \cdot 4 \mathrm{~g} . \\ \text { Riboflavin } & 400 \mu \mathrm{g} . \\ \text { Calcium pantothenate } & 800 \mu \mathrm{g} . \\ \text { Biotin } & 8 \mu \mathrm{g} . \\ \text { Thiamine } & 400 \mu \mathrm{g} . \\ \text { Uracil } & 30 \mu \mathrm{g} .\end{array}$

$\begin{array}{ll}\text { Adenine } & \mathbf{3 0} \mu \mathrm{g} . \\ \text { Pyridoxin HCl } & 2 \cdot 4 \mathrm{mg} . \\ p \text {-Aminobenzoic acid } & \mathbf{8 0} \mu \mathrm{g} . \\ \text { Nicotinic acid } & \mathbf{1 2 0 0} \mu \mathrm{g} . \\ \text { Choline chloride } & \mathbf{1 5} \mathrm{mg} . \\ \text { Pteroylglutamic acid } & \mathbf{0 \cdot 4} \mu \mathrm{g} . \\ \text { Distilled water to } 1 \mathrm{l} . & \end{array}$


The casein hydrolysate was prepared by hydrolysing light white soluble casein with $c$. $6 \mathrm{~N}$-hydrochloric acid, neutralizing, decolorizing with charcoal, removing calcium by the addition of phosphates and $\mathrm{pH}$ adjustment, and freeze-drying the final product. The growth factors were added as a stock solution. Sterilization was by filtration through Berkefeld-type candles after the $\mathrm{pH}$ had been adjusted to $7 \cdot 4$. This medium could be diluted to half strength with distilled water without affecting its ability to support adequate growth from small inocula of CN59. Thus solutions being tested for inhibition could be added in equal volume before inoculation. Copper was added to media and to media constituents as a solution of cupric chloride $\left(\mathrm{CuCl}_{2} \cdot 2 \mathrm{H}_{2} \mathrm{O}\right.$, Analar) in distilled water. Autoclaving was always for $10 \mathrm{~min}$. at $10 \mathrm{lb}$./sq.in. Nutrient agar was prepared with papain digest of horse muscle together with a horse-muscle extract, and was solidified with $1.2 \%$ South African agar (James P. Thol Ltd., 110 Fenchurch St., E.C. 3).

\section{RESULTS}

O'Meara \& Macsween $(1936,1937)$ showed that it was necessary to heat solutions of peptones containing copper in order to produce inhibition. This observation was confirmed with a freeze-dried tryptic digest of horse muscle prepared in this laboratory. A $1 \%$ solution of this peptone, which contained less than $0.05 \mathrm{mg}$. $\mathrm{Cu} / \mathrm{g}$., supported the growth of CN 59 whether sterilized by heat or by filtration, growth being consistently obtained at a dilution of $10^{-8}$ to $10^{-9}$ of the standard suspension of the test organism. On adding $10 \mathrm{mg}$. $\mathrm{Cu} / \mathrm{l}$. to simulate the copper level present in the solutions of peptones

Table 1. The inhibitory effect on Staphylococcus aureus of copper chloride added to unheated medium

Three tubes of medium were inoculated at each dilution of inoculum. The numbers indicate the number of tubes showing growth at each dilution. - $=$ no tubes inoculated at these dilutions.

\begin{tabular}{|c|c|c|c|c|c|c|c|c|}
\hline & \multicolumn{8}{|c|}{ Dilution of inoculum } \\
\hline & $10^{-2}$ & $10^{-3}$ & $10^{-4}$ & $10^{-5}$ & $10^{-6}$ & $10^{-7}$ & $10^{-8}$ & $10^{-9}$ \\
\hline Added copper & \multicolumn{8}{|c|}{ Growth response at $48 \mathrm{hr}$. } \\
\hline Nil & $\mathbf{3}$ & 3 & 3 & 3 & 3 & $\mathbf{3}$ & 3 & 2 \\
\hline $1 \cdot 0$ & - & - & - & - & - & 3 & 3 & 2 \\
\hline $10 \cdot 0$ & - & - & $\ldots$ & - & - & 3 & 3 & 0 \\
\hline $100 \cdot 0$ & - & - & - & - & - & 3 & 2 & 2 \\
\hline $1000 \cdot 0$ & 0 & o & 0 & 0 & 0 & 0 & 0 & 0 \\
\hline
\end{tabular}

examined by O'Meara \& Macsween and autoclaving for $10 \mathrm{~min}$. at $10 \mathrm{lb}$. the peptone solution completely inhibited the growth of CN59. The same amount of copper added as an autoclaved solution of copper chloride to a peptone solution previously sterilized by heat was without effect. Considerably higher amounts of copper were necessary to produce inhibition when the copper and peptone solutions were sterilized separately, the results in Table 1 showing that ionic copper was inhibitory to CN 59 only at a very high concentration. 


\section{The effect of container on the production of inhibition}

It was observed in the early stages of the work that peptone solutions containing copper became inhibitory only when autoclaved in tubes or bottles plugged with cotton-wool. When screw-capped bottles were used there was no inhibition (Table 2). This effect, for which no explanation has yet been

Table 2. Effect of heat and type of container on the inhibition of Staphylococcus aureus in $1 \%$ solution of tryptic digest of muscle $+10 \mathrm{mg} . \mathrm{Cu} / \mathrm{l}$.

Three tubes were inoculated at each dilution of inoculum. Symbols as in Table 1.

Dilution of inoculum

Method of

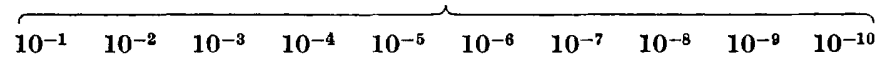
sterilization Growth response at $48 \mathrm{hr}$. and closure

Autoclaved (screwcapped bottles) Autoclaved (plugged
bottles)

Candled (screw-

capped bottles)

Candled (plugged bottles)

\begin{tabular}{|c|c|c|c|c|c|c|c|c|c|}
\hline \multicolumn{10}{|c|}{ Dilution of inoculum } \\
\hline $10^{-1}$ & $10^{-2}$ & $10^{-3}$ & $10^{-4}$ & $10^{-5}$ & $10^{-6}$ & $10^{-7}$ & $10^{-8}$ & $10^{-9}$ & $10^{-10}$ \\
\hline \multicolumn{10}{|c|}{ Growth response at $48 \mathrm{hr}$. } \\
\hline 3 & $\mathbf{3}$ & 3 & $\mathbf{3}$ & 3 & 3 & 3 & 3 & 1 & 0 \\
\hline $\mathbf{3}$ & $\mathbf{0}$ & 0 & 0 & 0 & 0 & $\mathbf{0}$ & $\mathbf{0}$ & $\mathbf{0}$ & $\mathbf{0}$ \\
\hline $\mathbf{3}$ & 3 & 3 & $\mathbf{3}$ & 3 & 3 & 3 & 3 & 1 & $\mathbf{0}$ \\
\hline 3 & $\mathbf{3}$ & 3 & 3 & 3 & $\mathbf{3}$ & $\mathbf{3}$ & 3 & $\mathbf{0}$ & $\mathbf{0}$ \\
\hline
\end{tabular}

obtained, appeared to be a function of the tightness of the seal made by the rubber disk in the screw cap with the bottle top. When this seal was prevented from forming by laying a cotton thread across the top of the bottle or by using a bottle with a chipped top, no protection was obtained and the heated medium became inhibitory. Sealed ampoules were as effective as screw-capped containers in preventing inhibition and therefore protection was almost certainly due to the air-tightness of the seal made by the rubber liner in the screw cap and not to the action of some chemical in the rubber liner. Replacement of cotton-wool plugs by caps or vice versa, after autoclaving, did not affect inhibition. Inhibitory material was therefore always prepared in plugged containers, although after heating this material was usually filled aseptically into sterile $1 \mathrm{oz}$. screw-capped bottles as these were more convenient for testing.

\section{The inhibitory effect of copper in partially defined medium}

Tryptic digest of muscle was unsuitable for continuing the investigation because of its complex composition. The partially defined medium made from acid hydrolysed casein with added growth factors was therefore tested to see whether the inhibitory phenomena could be reproduced. When this medium, to which $10 \mathrm{mg}$. $\mathrm{Cu} / \mathrm{l}$. had been added, was autoclaved in plugged containers it became inhibitory, whereas medium to which the same amount of copper had been added as a sterile solution was not inhibitory. The protective action of the screw-capped bottle was also observed and the results resembled in every way those obtained with tryptic digest of muscle. Inhibition was produced at copper concentrations as low as $2 \mathrm{mg}$./l., but $10 \mathrm{mg}$./l. was chosen 
for most of the experiments as being nearer the level of copper in the peptone solutions used by O'Meara \& Macsween $(1936,1937)$.

Autoclaving various components of casein medium with copper before mixing with the remainder showed that inhibition arose from interaction of copper with the acid-hydrolysed casein and not with the growth factors. Of the amino acids present in casein only cystine produced an inhibitory solution when autoclaved with copper, although this amino acid autoclaved alone was inactive. It was possible therefore that an oxidation or degradation product of cystine produced during autoclaving was responsible for inhibition, copper perhaps being involved as a catalyst. Cystine disulphoxide, cysteine sulphinic acid, di- $\beta$-mercapto-di-propionic acid, ethyl disulphide and cysteic acid, all possible degradation products of cystine, were tested but none was inhibitory. Attempts were therefore made to isolate the inhibitory substance in amounts sufficient for its identification.

Testing for inhibition by the dilution technique was time-consuming and a simpler test was sought. The inhibitory factor was expected to be an easily diffusible substance of comparatively low molecular weight. Plates of nutrient agar were therefore seeded with the test organism and the material under examination placed on the plates in 'fish spine' beads as used in antibiotic plate tests. Using the dilution technique it had been found that inhibitory casein hydrolysate could be diluted up to 8 times and still retain its ability to inhibit growth of CN59. It was expected that zones of inhibition would be seen surrounding fish-spine beads containing undiluted inhibitory medium. Repeated attempts to demonstrate zones were without success, although growth was inhibited directly beneath the bead. The inhibitory factor therefore appeared unable to diffuse in agar. This failure to diffuse could be explained if the substance were a colloid. To test this possibility a solution of cystine (20 mg./l.) and copper (10 mg./l. as chloride) in 0.01 M-phosphate buffer $(\mathrm{pH} \mathrm{7.4)}$ was autoclaved and the resulting inhibitory solution, which was a clear golden brown in colour, was dialysed against running tap water for $24 \mathrm{hr}$. The colour was retained by the dialysis membrane, and the residue in the sac, which was free from ninhydrin-positive substances, was still inhibitory when added to casein medium. Hence the inhibitory substance formed on autoclaving cystine with copper was colloidal and probably brown in colour.

Among the ultimate degradation products of cystine is hydrogen sulphide which is readily detected with lead acetate paper when a solution of cystine is heated. Copper present during the heating of a solution of cystine might therefore be expected to form colloidal copper sulphide, the sulphides of many heavy metals being colloidal in dilute solution. A solution of hydrogen sulphide, standardized in the usual way with iodine, was added in graded amounts to a copper chloride solution containing $10 \mathrm{mg}$. $\mathrm{Cu} / \mathrm{l}$. in an attempt to simulate the possible formation of copper sulphide from cystine. The final $\mathrm{H}_{2} \mathrm{~S}$ concentrations lay between 1 and $5 \mathrm{mg}$./l., and it was found that hydrogen sulphide was not toxic for the test organism at these concentrations. The clear brown solutions obtained matched very closely the appearance of autoclaved solutions of cystine and copper, the colour increasing in intensity with increasing 


\section{Inhibition by metal sulphides and sulphur}

hydrogen sulphide concentration. When boiled, these solutions remained clear though the colour changed to green, but they became unstable and flocculated when mixed with medium. The unheated brown solutions could be sterilized by filtration through candles, although a certain amount of coloured material was adsorbed in the process. The candled solutions were stable and inhibited the test organism when added to casein hydrolysate medium. It was concluded that copper sulphide was the inhibitory substance produced when casein hydrolysate or cystine solutions were autoclaved with copper.

To study the inhibitory effect of colloidal copper sulphide on bacteria it was necessary to prepare a sol which was reproducible, stable and free from either hydrogen sulphide or excess copper salt. After preliminary experiments the following procedure was devised. A solution of hydrogen sulphide made by passing the gas through distilled water for $15 \mathrm{~min}$. was standardized with iodine and diluted to contain $3 \mathrm{mg}$. $\mathrm{H}_{2} \mathrm{~S} / 100 \mathrm{ml}$. One hundred $\mathrm{ml}$. of this solution was added slowly with stirring to $900 \mathrm{ml}$. of distilled water containing $30 \mathrm{mg}$. $\mathrm{CuCl}_{2} \cdot 2 \mathrm{H}_{2} \mathrm{O}$. A clear golden-brown solution was obtained which was dialysed against distilled water for $\mathbf{2 4} \mathrm{hr}$. The material retained by the dialysis membrane was sterilized by filtration through a Berkefeld-type candle. By using small candles and filtering as large a volume of solution as possible, the loss of copper on candling could be decreased to less than $30 \%$ and the sterile solution obtained was still strongly coloured and could be diluted up to 8 times without marked loss of activity. These inhibitory solutions were standardized on their copper content which was determined by oxidizing a sample with nitric acid and determining the copper colorimetrically with sodium diethyldithiocarbamate. Copper sulphide sols prepared by this technique were stable for several weeks and were rejected when a distinct green shade became apparent. They were used for determining inhibitory levels of copper sulphide and also for investigating substances capable of abolishing the inhibition.

To find the level at which copper sulphide ceased to inhibit the test organism, dilutions of a copper sulphide sol prepared as above were made in casein hydrolysate medium. Table 3 shows that the inhibitory effect increased with increasing sulphide concentration and there was little increase in growth after $48 \mathrm{hr}$. A different result was obtained when a similar experiment was made with a sol which had been dialysed for $48 \mathrm{hr}$. instead of $24 \mathrm{hr}$. This sol had a greenish colour, indicating a change towards a larger particle size, although it was still clear and apparently stable. On incubating for several days the medium to which the sol had been added, growth equal to that of the control was obtained even with the highest copper sulphide concentration. Inhibitory action therefore decreased with increase in particle size of the colloid.

The inhibitory material formed when tryptic digest of muscle $(1 \%)$ was autoclaved with copper $(10 \mathrm{mg}$./l.) was shown to be colloidal by dialysis. The inhibitory substance was therefore most probably colloidal copper sulphide. Analysis before and after dialysis showed that $\mathbf{7 4} \%$ of the copper initially added had been immobilized on autoclaving and failed to pass through the dialysis membrane in $48 \mathrm{hr}$. A similar experiment with casein hydrolysate 
medium indicated a much greater loss of copper on dialysis, only $15 \%$ of the original copper remaining after $48 \mathrm{hr}$. The larger amount of copper sulphide formed in the tryptic digest was probably a reflexion of its higher cystine content. Paper chromatography showed that little free cystine was present in the tryptic digest, most of the cystine being combined in peptides. As solutions of glutathione autoclaved with copper were inhibitory to CN59 whereas solutions of this peptide heated alone were inactive it is probable that the cystinecontaining peptides in tryptic digest of muscle produced the hydrogen sulphide necessary for copper sulphide formation.

Table 3. The inhibition of Staphylococcus aureus by colloidal copper sulphide added to casein hydrolysate medium

Three tubes inoculated at each dilution of inoculum. Symbols as in previous tables.

Dilution of inoculum

\begin{tabular}{|c|c|c|c|c|c|c|c|c|}
\hline \multirow{2}{*}{$\begin{array}{l}\text { Duration of } \\
\text { incubation }\end{array}$} & \multirow{2}{*}{$\begin{array}{l}\text { Added copper } \\
\text { sulphide sol } \\
(\mu \mathrm{g} . \mathrm{Cu} / \mathrm{ml} .)\end{array}$} & $10^{-3}$ & $10^{-4}$ & $10^{-5}$ & $10^{-6}$ & $10^{-7}$ & $10^{-8}$ & $10^{-9}$ \\
\hline & & \multicolumn{7}{|c|}{ Growth response } \\
\hline \multirow[t]{4}{*}{$24 \mathrm{hr}$. } & Nil & 3 & 3 & 3 & 3 & 3 & 2 & 0 \\
\hline & 0.34 & 3 & 3 & 2 & 0 & 0 & 0 & 0 \\
\hline & 0.68 & 3 & 0 & 0 & 0 & 0 & 0 & 0 \\
\hline & $1 \cdot 36$ & 0 & 0 & 0 & 0 & 0 & 0 & 0 \\
\hline \multirow[t]{4}{*}{$48 \mathrm{hr}$. } & Nil & 3 & 3 & 3 & $\mathbf{3}$ & 3 & 3 & 1 \\
\hline & $\mathbf{0 . 3 4}$ & 3 & 3 & $\mathbf{3}$ & 3 & 3 & 2 & 1 \\
\hline & 0.68 & 3 & $\mathbf{3}$ & 0 & 0 & 0 & 0 & 0 \\
\hline & $1 \cdot 36$ & o & 0 & 0 & 0 & 0 & 0 & 0 \\
\hline \multirow[t]{4}{*}{7 days } & Nil & 3 & 3 & 3 & 3 & 3 & 3 & 1 \\
\hline & 0.34 & 3 & 3 & 3 & 3 & 3 & 3 & 2 \\
\hline & 0.68 & 3 & 3 & 1 & 0 & 0 & 0 & 0 \\
\hline & $1 \cdot 36$ & 2 & 0 & 0 & 0 & 0 & 0 & 0 \\
\hline
\end{tabular}

The inhibitory effect of colloidal sulphur on the growth of Staphylococcus aureus

Whilst this work was in progress Schuhardt and co-workers (Schuhardt, Rode, Foster \& Oglesby, 1949; Schuhardt, Rode \& Oglesby, 1949; Schuhardt, Rode, Oglesby \& Lankford, 1950) had been investigating the anti-brucella activity of heated cystine solutions. In many ways this inhibition resembled that of copper sulphide. It was shown eventually (Schuhardt, Rode, Oglesby \& Lankford, 1952) that the anti-brucella factor was colloidal sulphur. The effect of sulphur on CN59 was therefore examined to see in what respects it behaved like colloidal copper sulphide towards this organism. Autoclaved cystine solutions were non-inhibitory for CN 59 at $50 \mathrm{mg}$. cystine/l. and this organism therefore appeared less susceptible to sulphur than the Brucella spp. studied by Schuhardt. Autoclaved cystine solutions were found by Fildes \& Richardson (1937) to be inhibitory for staphylococci. The failure to demonstrate such inhibition in the present work suggests that Fildes \& Richardson were perhaps observing copper sulphide inhibition, copper being present as a contaminant in their samples of cystine. A colloidal sulphur suspension prepared by the 
technique of Schuhardt et al. (1952) when added aseptically in graded amounts to casein medium was inhibitory to CN59. The results summarized in Table 4 show that growth was delayed, particularly at higher sulphur concentrations, but there was a tendency for inhibition to disappear on prolonged incubation. In this sulphur differed from colloidal copper sulphide.

Table 4. The inhibition of Staphylococcus aureus by collodial sulphur added to casein hydrolysate medium

Three tubes inoculater at each dilution of inoculum. Symbols as in previous tables.

\begin{tabular}{|c|c|c|c|c|c|c|c|c|}
\hline \multirow{3}{*}{$\begin{array}{l}\text { Duration of } \\
\text { incubation }\end{array}$} & \multirow{3}{*}{$\begin{array}{l}\text { Added colloidal } \\
\text { sulphur } \\
(\mu \mathrm{g} . \mathrm{S} / \mathrm{ml} .)\end{array}$} & \multicolumn{7}{|c|}{ Dilution of inoculum } \\
\hline & & $10^{-3}$ & $10^{-4}$ & $10^{-5}$ & $10^{-6}$ & $10^{-7}$ & $10^{-8}$ & $10^{-9}$ \\
\hline & & \multicolumn{7}{|c|}{ Growth response } \\
\hline \multirow[t]{5}{*}{$24 \mathrm{hr}$. } & Nil & $\mathbf{3}$ & 3 & $\mathbf{3}$ & 3 & $\mathbf{3}$ & 2 & 0 \\
\hline & $0 \cdot 15$ & $\mathbf{3}$ & 3 & 3 & $\mathbf{3}$ & $\mathbf{3}$ & $\mathbf{3}$ & $\mathbf{0}$ \\
\hline & 0.60 & $\mathbf{0}$ & 0 & $\mathbf{0}$ & 0 & $\mathbf{0}$ & 0 & $\mathbf{0}$ \\
\hline & $1 \cdot 20$ & $\mathbf{0}$ & $\mathbf{0}$ & $\mathbf{0}$ & $\mathbf{0}$ & $\mathbf{0}$ & $\mathbf{0}$ & $\mathbf{0}$ \\
\hline & $2 \cdot 00$ & $\mathbf{0}$ & 0 & $\mathbf{0}$ & 0 & $\mathbf{0}$ & 0 & 0 \\
\hline \multirow[t]{5}{*}{$48 \mathrm{hr}$. } & Nil & $\mathbf{3}$ & $\mathbf{3}$ & 3 & 3 & 3 & $\mathbf{3}$ & 0 \\
\hline & $0 \cdot 15$ & 3 & 3 & 3 & $\mathbf{3}$ & $\mathbf{3}$ & $\mathbf{3}$ & $\mathbf{1}$ \\
\hline & $0 \cdot 60$ & $\mathbf{3}$ & $\mathbf{3}$ & $\mathbf{3}$ & 2 & 3 & 1 & $\mathbf{0}$ \\
\hline & $1 \cdot 20$ & 1 & 0 & $\mathbf{0}$ & $\mathbf{0}$ & $\mathbf{0}$ & 0 & $\mathbf{0}$ \\
\hline & $\mathbf{2 \cdot 0 0}$ & 0 & 0 & $\mathbf{0}$ & $\mathbf{0}$ & $\mathbf{0}$ & $\mathbf{0}$ & 0 \\
\hline \multirow[t]{4}{*}{7 days } & Nil & $\mathbf{3}$ & $\mathbf{3}$ & $\mathbf{3}$ & $\mathbf{3}$ & $\mathbf{3}$ & $\mathbf{3}$ & $\mathbf{0}$ \\
\hline & $0 \cdot 15$ & 3 & 3 & $\mathbf{3}$ & $\mathbf{3}$ & 3 & 3 & 1 \\
\hline & $0 \cdot 60$ & $\mathbf{3}$ & 3 & 3 & 3 & $\mathbf{3}$ & 3 & 1 \\
\hline & $2 \cdot 00$ & 3 & 3 & $\mathbf{3}$ & 2 & $\mathbf{0}$ & $\mathbf{0}$ & 0 \\
\hline
\end{tabular}

\section{The reversal of copper sulphide and sulphur inhibition}

Schuhardt et al. (1952) found a number of substances which removed the inhibitory action of sulphur for Br. abortus, among them cystine, mercaptoacetic acid and various inorganic sulphur compounds. Some of these substances were tested to see whether they were equally effective in preventing the inhibition of CN59 by sulphur and also whether they effected the inhibition of this organism by colloidal copper sulphide. The colloidal sulphur and copper sulphide solutions were prepared as before. The former was opalescent and gave a strong Tyndall effect, whereas the copper sulphide was crystal clear with little Tyndall effect. Colloidal sulphur was added to casein medium to give a final concentration of $1.6 \mu \mathrm{g}$. S/ml. and the copper sulphide a concentration of $2.8 \mu \mathrm{g}$. CuS $/ \mathrm{ml}$. Examination for growth was made after 24 and $48 \mathrm{hr}$. incubation, casein medium being used as a control.

Cystine, cysteine and mercaptoacetic acid were without effect on copper sulphide inhibition, although all these substances overcame the inhibitory action of sulphur. On the assumption that copper sulphide might exert its inhibitory action by blocking the formation from cysteine or cystine of a simple degradation product necessary for growth, $\beta$-mercaptopropionic acid, the product of deamination of cysteine, was examined. This substance completely reversed inhibition by both sulphur and copper sulphide. With the 
latter the growth was coloured brown, indicating that copper sulphide was absorbed by the bacteria. Sodium sulphite also removed inhibition. As, however, it is not a possible source of sulphur for staphylococci (Fildes \& Richardson, 1937) the mechanism by which it reverses inhibition is difficult to understand.

Examination of the two sols revealed large differences in particle size. Sulphur sols prepared by the method of Schuhardt et al. (1952) lost their inhibitory properties when passed through the coarsest grade of membrane filter (Apis Engineering Co.), indicating a particle size greater than $3000 \mathrm{~m} \mu$., whereas copper sulphide sols tested with Gradocol membranes kindly supplied by Prof. C. L. Oakley contained inhibitory particles lying between 230 and $330 \mathrm{~m} \mu$. Differences in behaviour between the two colloids therefore might reflect this large difference in particle size. It is possible that if finer sulphur suspensions could have been produced these would have behaved more like the copper sulphide sols in experiments on annulment of the inhibitions. The work of Libenson et al. (1953) suggests that these finer suspensions of sulphur would also have been more inhibitory. The difficulty of producing colloidal sulphur solutions of any particular particle size prevented this idea being tested.

\section{Inhibition of micro-organisms by colloidal copper sulphide}

A number of workers have studied the action of colloidal sulphur on microorganisms (Lawson, 1934; Massey \& Snyder, 1936; Weld \& Gunther, 1947; Libenson et al. 1953), and in general they found it more inhibitory for Grampositive than Gram-negative organisms. Inhibitory casein hydrolysate medium was prepared by adding $10 \mathrm{mg}$. $\mathrm{Cu} / \mathrm{l}$. and autoclaving. Its effect on the growth of a number of common organisms was examined, unheated medium being used as a control. All strains of staphylococci tested (10) were inhibited, as were representative strains of Bacillus subtilis, B. polymyxa, B. cereus, and B. pumilus. Brucella abortus and Br. melitensis were inhibited whilst Br. bronchisepticus was unaffected. Vibrio comma, Pseudomonas aeruginosa, Aerobacter aerogenes, Escherichia coli, Salmonella typhi, Shigella paradysenteriae, Proteus vulgaris and Pr. mirabilis were not inhibited. In general copper sulphide behaved like sulphur in being more active against Grampositive than Gram-negative organisms.

\section{The inhibition of bacterial growth by sulphides of heavy metals other than copper}

Although O'Meara \& Macsween (1936, 1937) showed that copper was responsible for the heat-induced inhibitory action of peptones, there appeared no reason why other heavy metals whose sulphides were insoluble should not also be inhibitory. Few heavy metal sulphides are as insoluble as copper sulphide, and their formation in autoclaved medium therefore was unlikely since insufficient hydrogen sulphide would be produced for their solubility products to be exceeded. Hydrogen sulphide formed during growth of an organism might, however, lead to sulphide formation and the effects of these 
sulphides on staphylococci was therefore investigated. The metals chosen for examination were iron, manganese, nickel, cobalt, zine, cadmium, mercury, lead, silver and gold. Many of these metals are present in peptone, usually in traces but sometimes in considerable amounts. Silver and gold, though not likely to be present in media, were of interest because of their close relationship with copper in the Periodic Table. Neither of these metals could be added as salts to liquid medium and autoclaved, since the metal ion was toxic for CN 59. Their sulphide sols, however, were readily prepared by the technique used for preparing copper sulphide. These sols were a clear golden brown and were more stable than colloidal copper sulphide in that they could be boiled without change of colour. When added to casein hydrolysate medium they inhibited the test organism but had only about one-tenth the activity of copper sulphide. Attempts to produce stable sulphide sols of other heavy metals were unsuccessful; they flocculated when they were added to, or were incubated with, the culture medium, so there was little prospect of settling the question of the inhibitory action of these sulphides until some method for stabilizing them was devised.

It was found that the inhibitory effect of copper sulphide could be demonstrated by placing a disk of filter-paper impregnated with sodium sulphide on the surface of a poured plate of nutrient agar inoculated with CN59 and containing copper chloride. Other heavy metals were tested by this technique as it offered a solution of the problem of stabilization. The metal was incorporated in the nutrient agar usually as the chloride or sulphate at a level of $10 \mathrm{mg} . / \mathrm{l}$. Sodium sulphide solutions with concentrations between 1 and $2.5 \%(\mathrm{w} / \mathrm{v})$ were used for impregnating the disks and CN59 was the test organism. $\mathrm{Co}, \mathrm{Ni}, \mathrm{Pb}$, and $\mathrm{Zn}$ showed no inhibition either in the medium itself or round the sodium sulphide disk but $\mathrm{Cd}$ gave slight inhibition round the disk. Copper gave a zone of complete inhibition with clear-cut edges, together with a larger shallow zone of decreased growth (Pl. 1, fig. 2). The second zone, which does not show well in the photograph, was thought to be due to hydrogen sulphide which would diffuse through the plate faster than the sodium sulphide from which it was formed by hydrolysis. Mercury completely inhibited growth in the plate, but heavy growth was obtained round the sodium sulphide disk. Iron and manganese both gave sharply defined zones of inhibition round the disk (Pl. 1, figs. 3, 4) but the zones were not as big as with copper nor was any secondary zone seen. Disks impregnated with sodium sulphide on plates of nutrient agar were used as controls, but in no case was inhibition observed. Indicator solution was flooded over plates which showed inhibitory zones to see whether large $\mathrm{pH}$ changes had occurred because of interaction of metal salt and sodium sulphide or hydrolysis of sodium sulphide; no changes were detected and the zones therefore appear to be due to sulphide formation. Copper produced by far the most inhibitory sulphide but the fact that iron and manganese sulphide could inhibit the growth of staphylococci though relatively weakly was of considerable interest; the possible significance of this finding is discussed later. 


\section{DISCUSSION}

How colloidal copper sulphide exerts its inhibitory action is not known. It is an extremely insoluble substance having a solubility product of $8.5 \times 10^{-44}$ (Ephraim, 1943) and is not very reactive. It is therefore unlikely to combine with media constituents and render them unavailable to the organism. Being a colloid it cannot penetrate into the cell, but it might be adsorbed on the cell wall and there interfere with the ingress of essential metabolites or with enzymic transformations necessary for growth. The reversal of the inhibition by $\beta$-mercaptopropionic acid but not by cysteine or cystine suggests that specific enzyme systems are being interfered with, possibly those concerned with the utilization of sulphydryl groups which Fildes \& Richardson (1937) showed were essential for the growth of staphylococci. Silver and gold sulphides are considerably less active than copper sulphide and as all these metals are closely allied in the Periodic System this may indicate a steric factor, the molecular dimensions of copper sulphide being such that it fits into an enzyme system in place of the usual substrate more readily than either gold or silver sulphides.

It might seem that colloidal sulphur is acting on the cocci in a different way from colloidal copper sulphide as its action is so easily reversed with cystine, cysteine, and mercaptoacetic acid, whereas copper sulphide inhibition is unaffected by these compounds. However, Schuhardt et al. (1952) showed with brucellas that annulment of sulphur inhibition could in many cases be explained by the chemical reaction of sulphur with the annulling agent or with media constituents. The difference in behaviour of the two colloids may therefore be a reflexion of differences in chemical reactivity rather than a fundamental difference in mode of action. The problem is complicated by the fact that it is impossible to be certain that apparent annulment of inhibition is not due to flocculation of the inhibitory colloid. It is much more difficult to prepare stable colloidal sulphur suspensions than copper sulphide sols, and it is noticeable that when the particle size of the copper sulphide sol is increased by heating, the resultant sols are much less stable and flocculate readily. This flocculation is easily detected, since copper sulphide is coloured. It is not easy to detect the flocculation of dilute sulphur suspensions, particularly in the presence of bacteria.

Because of the work of O'Meara \& Macsween (1936, 1937) copper has largely been eliminated from commercial peptones and precautions are normally taken to prevent its entering culture media during preparation. The lack of toxicity of most common heavy metal sulphides, coupled with the fact that those with an inhibitory action have a larger solubility product than copper sulphide, means that the sulphides of metals other than copper do not present a problem in media making. A number of bacteria produce sufficient hydrogen sulphide during growth for the solubility product of the sulphides of these metals then to be exceeded. The darkening of media during the growth of many anaerobes, for instance, is commonly attributed to the production of colloidal iron sulphide. The demonstration in the present work of the bio- 
logical activity of iron sulphide may therefore have some importance. It seems unlikely that iron sulphide would affect the growth of these organisms, since heavy growth would be necessary to produce sufficient hydrogen sulphide for its formation, but it might well affect enzyme systems which produce special metabolic products, such as bacterial toxins, or might even interact with such products and decrease or abolish their activity. Cooked meat particles are often added to anaerobic media to ensure good yields of toxins. Besides providing a nidus for initiating growth (Knight, 1941) and introducing reducing systems to assist in the production of anaerobic conditions (Lepper \& Martin, 1929), the meat particles might also help toxin production by absorbing inhibitory colloidal sulphides. If this were so, even better results would be expected if these colloids could be excluded from contact with the growing bacteria. From this point of view the experiments of Sterne \& Wentzel (1950) with Clostridium botulinum are of interest. They grew this organism in cellophan sacs, the culture medium being on the outside and the organism inoculated into saline inside the sac. Toxins 50 to 100 times as potent as those prepared in the conventional way were obtained. $\mathrm{Cl}$. botulinum is a strong hydrogen sulphide producer and this gas would pass rapidly through the membrane into the surrounding medium where it could react with iron and other heavy metals. The sulphides formed would be prevented by the cellophan membrane from re-entering the saline containing the growing organisms and would not therefore be able to affect either the growth or toxin-producing capacity of the organisms.

Although it is not known why copper-containing media fail to develop inhibition when autoclaved in screw-capped bottles or sealed ampoules it is possible to suggest a mechanism for this failure. If the decomposition of cystine on heating is a reversible reaction, an equilibrium will be attained when the heating is carried out in a closed system such as a sealed ampoule. Under any given conditions of temperature and pressure a limited amount of hydrogen sulphide would therefore be produced, and if this were insufficient with the copper present to exceed the solubility product of copper sulphide, the resulting solution would not be inhibitory. However, if hydrogen sulphide could escape, as would be the case with cotton-wool plugged containers, the equilibrium would be upset and the breakdown of cystine would proceed throughout the heating period. Much of the extra hydrogen sulphide produced would pass through the plug but more would also be available for reaction with any copper present and the likelihood of the solubility product of copper sulphide being exceeded would be much increased.

I wish to thank Miss Ann Norton for her invaluable technical assistance throughout this work.

\section{REFERENCES}

Ephraim, F. (1943). Inorganic Chemistry. London: Gurney and Jackson.

Fildes, P. \& Richardson, G. M. (1937). The nutrition of Staphylococcus aureus: sulphur requirements. Brit. J. exp. Path. 18, 292.

KNIGHT, B. C. J. G. (1941). Factors in the cultivation of anaerobic bacteria. Chem. \& Ind. (Rev.), 60, 369. 
Lawson, G. B. (1934). The inhibitory action of sulphur on the growth of tubercle bacilli. Amer. Rev. Tuberc. 29, 651.

Lepper, E. \& Martin, C. J. (1929). The chemical mechanisms exploited in the use of meat media for the cultivation of anaerobes. Brit. J. exp. Path. 10, 327.

Libenson, L., Hadley, F. P., Mcilroy, A. P., Wentzel, V. M. \& Mellon, R. (1953). Antibacterial effect of elemental sulfur. J. infect. Dis. 93, 28.

MASSEY, A. B. \& SNYDER, G. E. (1936). Inhibitory action of colloidal sulphur in Corpers agar on the growth of 4 strains of Mycobacterium tuberculosis var. hominis. Amer. J. publ. Hlth. 26, 811.

O'Meara, R. A. Q. \& Macsween, J. C. (1936). The failure of staphylococcus to grow from small inocula in routine laboratory media. J. Path. Bact. 43, 373.

O'Meara, R. A. Q. \& Macsween, J. C. (1937). The influence of copper in peptones on the growth of certain pathogens in peptone broth. J. Path. Bact. 44, 225.

Proom, H. \& Worwod, A. J. (1949). The examination by partition paper chromatography of the nitrogen metabolism of bacteria. J. gen. Microbiol. 3, 319.

Schunardt, V. T., Rode, L. J., Foster, J. W. \& Oglesby, G. (1949). An antibrucella factor in peptones. J. Bact. 57, 1.

Schuhardt, V. T., Rode, L. J. \& Oglesby, G. (1949). Toxicity of certain amino acids for brucellae. J. Bact. 58, 665 .

Schuhardt, V. T., Rode, L. J., Oglesby, G. \& Lankford, C. E. (1950). The development of peptone toxicity for brucellae with ageing and the correlation of this toxicity with the probable oxidation of cystine. J. Bact. 60,655 .

Schuhardt, V. T., Rode, L. J., Oglesby, G. \& Lankford, C. E. (1952). The toxicity of elemental sulphur for brucellae. J. Bact. 63, 123.

Sterne, M. \& Wentzel, L. M. (1950). A new method for the large-scale production of high-titre botulinum formol-toxoid Types $\mathrm{C}$ and D. J. Immunol. 65, 175.

Weld, J. T. \& GunTHer, A. (1947). The antibacterial properties of sulphur. J. exp. Med. 85, 531.

\section{EXPLANATION OF PLATE}

Growth of Staphylococcus aureus round disks impregnated with sodium sulphide solution $(2.5 \%)$ on nutrient agar pour plates, with or without added salts.

Fig. 1. Nutrient agar.

Fig. 2. Nutrient agar with $10 \mathrm{mg} . \mathrm{Cu}^{\prime \prime} / \mathrm{l}$.

Fig. 3. Nutrient agar with $10 \mathrm{mg}$. $\mathrm{Fe}^{\prime \prime \prime} / \mathrm{l}$.
Fig. 4. Nutrient agar with $10 \mathrm{mg}$. $\mathrm{Mn}^{\prime \prime} / \mathrm{l}$. Fig. 5. Nutrient agar with $10 \mathrm{mg}$. Ni/l." Fig. 6. Nutrient agar with $10 \mathrm{mg}$. $\mathrm{Hg}^{\prime \prime} / \mathrm{l}$. 
Journal of General Microbiology, Vol. 10, No. 3

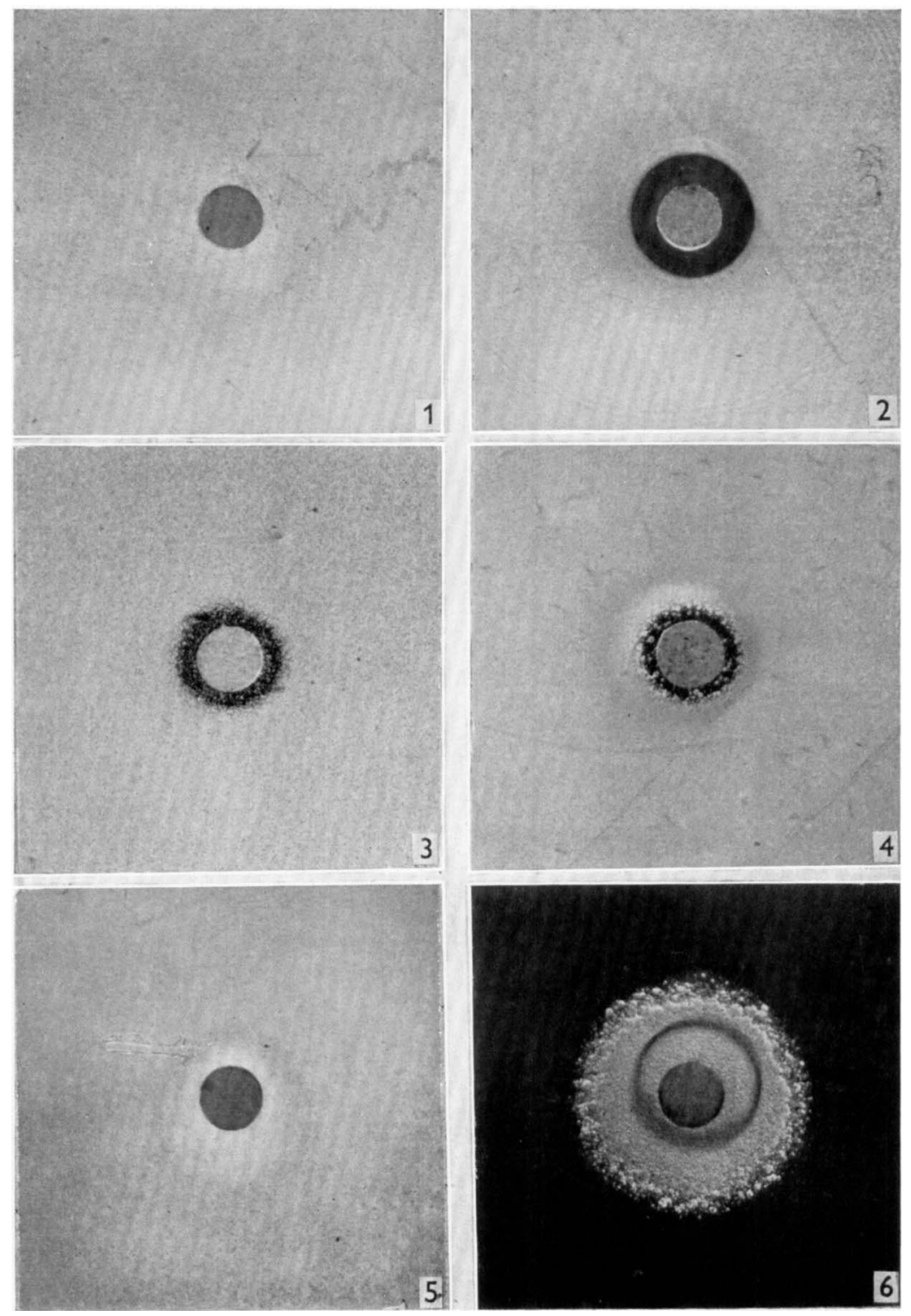

A. J. Woiwod-Inhibition by metal sulphides and sulphur. Plate 1 